\title{
Novel Biotransformation of Digoxigenin by Colletotrichum lini AS3. 4486
}

\author{
Chaojun $\mathrm{He}^{1, \mathrm{a}^{*}}$, Jingyan Niu ${ }^{2, \mathrm{~b}}$, Yumin Yang ${ }^{3, \mathrm{c}}$, Zengbing $\mathrm{Liu}^{4, \mathrm{~d}}$ \\ ${ }^{1,3}$ Luoyang Normal University, College of Life Sciences, Luoyang 471022, Henan, P. R. China \\ ${ }^{2}$ Jiaozuo Teachers college, Institute of Technology, Jiaozuo 454000, Henan, P. R. China \\ ${ }^{4}$ Tianjin University of Science and Technology, College of Biotechnology, Tianjin 300457, P. R. \\ China \\ ahchj98@163.com, blaoniu526@sohu.com, ${ }^{\mathrm{c}} 791453209 @ q q . c o m,{ }^{\mathrm{d}} 112266 \mathrm{lzb} @ 163 . c o m$
}

Keywords: Digoxigenin, Digoxigenone, Colletotrichum lini AS3. 4486, Microbial Transformation.

\begin{abstract}
The biotransformation of digoxigenin by Colletotrichum lini AS3. 4486 was investigated. The conversion reaction was carried out in a $72 \mathrm{~h}$ process, and the sole products was isolated by column chromatography and elucidated as digoxigenone by HR-ESI-MS, ${ }^{1} \mathrm{H}-\mathrm{NMR},{ }^{13} \mathrm{C}-\mathrm{NMR}$ and single-crystal X-ray diffraction. The crystal of digoxigenone belongs to triclinic, space group P1 with 7.4017 (15), 7.7450 (15), 10.215 (2) $\AA$, $\alpha=99.51(3), \beta=94.70$ (3), $\gamma=114.97$ (3) ${ }^{\circ}, Z=1$. This study povides a new method for the synthesis of digoxigenone.
\end{abstract}

\section{Introduction}

Digoxin and digitoxin, the typical clinically used forms, are the drugs of choice for the treatment of congestive heart failure (CHF), acting as selective inhibitors of the $\mathrm{Na}^{+}, \mathrm{K}^{+}$-ATPase enzyme[1]. The mechanism of their action for the treatment of CHF arises from the inhibition of $\mathrm{Na}^{+}, \mathrm{K}^{+}$-ATPase, with a resulting increase in intracellular calcium concentrations[2, 3].

The biotransformation of steroidal compounds has been extensively studied, including conversion reactions of cardiac glycosides. So far the main reactions of cardenolide biotransformation were hydroxylation in different positions of the steroidal skeleton. It has been found to obtain derivatives of digitalis cardiotonics by plant cell cultures and the conversion of digitoxin into digoxin had been successful[4]. Digitoxigenin has been converted into digoxigenin and digoxigenone by Fusarium ciliatum and into 1 beta-hydroxydigitoxigenin,7 beta-hydroxydigitoxigenin, 8 beta-hydroxidigitoxigenin, and digitoxigenone by Cochliobolus lunatus [5, 6]. In this paper, we studied the biotransformation of digoxigenin by Colletotrichum lini AS3. 4486 and purified and identified the conversion product.

\section{Materials and methods}

\subsection{Strain and medium}

Colletotrichum lini AS3. 4486 was bought from Institute of Microbiology, Chinese Academy of Sciences. C. lini was maintained on potato dextrose agar slants (PDA), at $4{ }^{\circ} \mathrm{C}$.

\subsection{Culture conditions}

Two consecutive cultivation steps for C. lini AS3. 4486: in the first phase, we used a liquid medium with glucose $30 \mathrm{~g} \cdot \mathrm{L}^{-1}$, corn steep liquor $10 \mathrm{~g} \cdot \mathrm{L}^{-1}$ and tap water at $\mathrm{pH} 7.0,25{ }^{\circ} \mathrm{C}, 72 \mathrm{~h}$. The second phase was a fermentative phase where a richer liquid medium was employed containing glucose $30 \mathrm{~g} \cdot \mathrm{L}^{-1}$, corn steep liquor $10 \mathrm{~g} \cdot \mathrm{L}^{-1}$, soy meal $10 \mathrm{~g} \cdot \mathrm{L}^{-1}, \mathrm{NaNO}_{3} 2 \mathrm{~g} \cdot \mathrm{L}^{-1}, \mathrm{~K}_{2} \mathrm{HPO}_{4} 2 \mathrm{~g} \cdot \mathrm{L}^{-1}$, $\mathrm{KH}_{2} \mathrm{PO}_{4} 1 \mathrm{~g} \cdot \mathrm{L}^{-1}, \mathrm{KCl} 0.5 \mathrm{~g} \cdot \mathrm{L}^{-1}, \mathrm{MgSO}_{4} \cdot 7 \mathrm{H}_{2} \mathrm{O} 0.5 \mathrm{~g} \cdot \mathrm{L}^{-1}, \mathrm{FeSO}_{4} \cdot 7 \mathrm{H}_{2} \mathrm{O} 0.02 \mathrm{~g} \cdot \mathrm{L}^{-1}, \mathrm{pH} 7.0$.

\subsection{Chemicals}

Digoxin was obtained from Xi'an Shan-Chuan Biotechnology Co., Ltd (China). The silica gel column (200 300 mesh) was bought from Haiyang Chemical. \& special silica gel CO., Ltd (Qingdao). 
Digoxigenin was obtained by the acidic hydrolysis of digoxin. A portion of digitoxin $(1 \mathrm{~g})$ was dissolved in $\mathrm{CH}_{3} \mathrm{CH}_{2} \mathrm{OH}(50 \mathrm{~mL})$ under sonication, followed by addition of aqueous $1 \mathrm{~mol} / \mathrm{L} \mathrm{HCl} \mathrm{(1}$ $\mathrm{mL})$. The solution was heated at $90^{\circ} \mathrm{C}$, for $5 \mathrm{~h}$, followed by an extraction with $\mathrm{CHCl}_{3}(3 \times 100 \mathrm{~mL})$. The organic layer was neutralized with saturated $\mathrm{NaHCO}_{3}$ aqueous solution and concentrated until the residue (421 mg) was obtained.

\subsection{General biotransformation procedures}

The experiment was conducted in shaking flasks $(250 \mathrm{~mL})$ containing $40 \mathrm{~mL}$ liquid medium inoculated with $C$. lini AS3. 4486. The flasks were shaken at 25C with $210 \mathrm{rpm}$ for $24 \mathrm{~h}$. Digoxigenin was dissolved in ethanol $\left(50 \mathrm{~g} \cdot \mathrm{L}^{-1}\right)$ and distributed among the flasks $\left(0.34 \mathrm{~g} \cdot \mathrm{L}^{-1}\right)$, except one kept as a control, and then the reaction was allowed to proceed for $48 \mathrm{~h}$. The mycelium was filtered. The biomass and the broth were separately extracted with ethyl acetate $(100: 1 \mathrm{~g} / \mathrm{v}, 4: 1 \mathrm{v} / \mathrm{v})$ in a separator funnel. All extracts were combined and the solvents were evaporated under reduced pressure at 60C until a residue was produced.

\subsection{Purification of product}

The crude extracts were purified by Si gel column using chloroform/methanol $(25: 1, \mathrm{v} / \mathrm{v})$ and analyzed by TLC with the developing solvent (chloroform: methanol: benzene $=10: 2: 5, \mathrm{v} / \mathrm{v} / \mathrm{v}$ ).

\subsection{General analysis methods}

HR-MS spectra was recorded on a Bruker APEX. ${ }^{1} \mathrm{H}$ HMR, ${ }^{13} \mathrm{C}$ NMR and NOE difference spectra were measured on a Bruker AV400 Instrument $(400 \mathrm{MHz})$ with $\mathrm{CDCl}_{3}$ as the solvent. Chemical shifts $(\delta)$ are given in ppm and $\mathrm{J}$ couplings in $\operatorname{Hertz}(\mathrm{Hz})$.

Crystallographic measurement was performed using an Oxford Cryosystem device on a Rigaku Saturn CCD area-detector diffractometer with a graphite-monochromated Mo Ka radiation. The structure was solved by Direct Methods (Sheldrick) and refined by the full-matrix least-squares on all F2 with anisotropic displacement parameters for all non-hydrogen atoms using SHELXL-97 (Sheldrick). The $\mathrm{H}$ atoms of hyadroxyl were geometrically placed $\mathrm{O}-\mathrm{H}=0.82 \AA$ and refined as riding with $\operatorname{Uiso}(\mathrm{H})=1.5 \mathrm{Ueq}(\mathrm{O})$. The water $\mathrm{H}$ atoms were located from a difference map and refined freely.

\section{Results and Discussion}

Digoxigenin was subject to biotransformation by cultured cells of C. lini AS3. 4486. The conversion reaction proceeded efficiently, and substrate was almost entirely converted in $72 \mathrm{~h}$. The conversion was confirmed by TLC (shown in Fig. 1). The results revealed that the sole product with $\mathrm{R}_{\mathrm{f}}$ value of 0.35 was yielded. The product was purified by silica gel column chromatography, and identified by HR-ESI-MS, ${ }^{1} \mathrm{H}-\mathrm{NMR},{ }^{13} \mathrm{C}-\mathrm{NMR}$ and single-crystal X-ray diffraction.

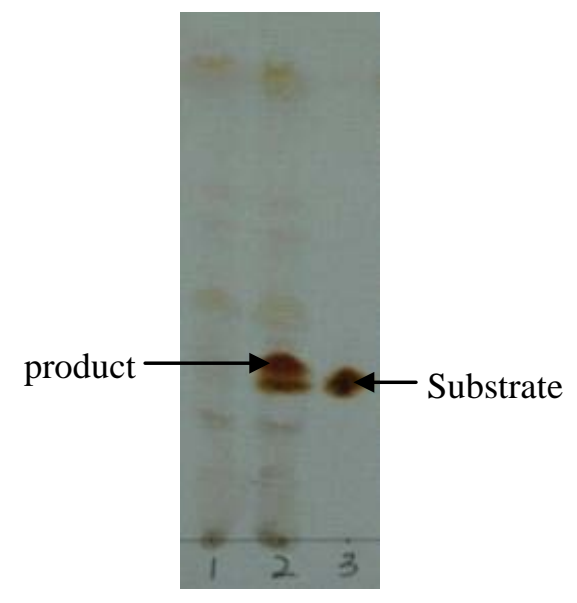

Fig. 1 The TLC spectrum on biotransformation of digoxigenin by C. lini AS3. 4486 
The product was a kind of white power; The HR-ESI-MS m/z 411.2142 [M+Na] ${ }^{+1} .{ }^{1} \mathrm{H}-\mathrm{NMR}$ (400 MHz in $\left.\mathrm{C}_{5} \mathrm{D}_{5} \mathrm{~N}\right): \delta_{\mathrm{H}} 0.88(3 \mathrm{H}, \mathrm{s}, \mathrm{Me}), 1.24(3 \mathrm{H}, \mathrm{s}, \mathrm{Me}), 3.74(1 \mathrm{H}, \mathrm{m}, \mathrm{H}-12), 5.25(1 \mathrm{H}, \mathrm{d}, \mathrm{H}-21 \mathrm{a}, \mathrm{J}=$ $18 \mathrm{~Hz}), 5.11(1 \mathrm{H}, \mathrm{d}, \mathrm{H}-21 \mathrm{~b}, \mathrm{~J}=18 \mathrm{~Hz}), 6.23(1 \mathrm{H}, \mathrm{H}-22) ;{ }^{13} \mathrm{C}-\mathrm{NMR}\left(400 \mathrm{MHz}\right.$ in $\left.\mathrm{C}_{5} \mathrm{D}_{5} \mathrm{~N}\right): \delta_{\mathrm{C}} 36.97$ (C-1), 37.27 (C-2), 211.19 (C-3), 42.41 (C-4), 43.97 (C-5), 27.06 (C-6), 21.91 (C-7), 41.58 (C-8), 33.57 (C-9), 35.37 (C-10), 30.80 (C-11), 74.43 (C-12), 56.85 (C-13), 85.29 (C-14), 30.87 (C-15), 27.91 (C-16), 46.66(C-17), 10.15(C-18), 22.57(C-19), 174.63 (C-20), 74.02 (C-21), 117.58 (C-22), 176.32 (C-23).

The high-resolution mass spectrum of the product, which showed a $[\mathrm{M}+\mathrm{Na}]^{+1}$ peak at $\mathrm{m} / \mathrm{z}$ 411.2142, corresponding to the formula $\mathrm{C}_{23} \mathrm{H}_{32} \mathrm{O}_{5}, 2$ amu higher than the substrate.

The spectroscopic analysis of digoxigenin was previously reported by Fernã C. Braga[5].The ${ }^{1} \mathrm{H}$ NMR spectrum displays signals at $\delta 3.74, \delta 5.25$ and $\delta 6.23$ corresponding to the the hydroxyl group at C-3 and the $\alpha, \beta$ unsaturated lactone protons respectively, as well as the appearance of the methyl groups functional group ( $\delta 0.88$ and $\delta 1.23)$. The direct evidence presented by the authors for formation of the digoxigenin was a methane hydrogen bearing a hydroxyl group $(\delta 4.14)$.

Spectroscopic analysis of of the product showed that the signals in the ${ }^{1} \mathrm{H}$-NMR spectrum of digoxigenin wholly appear in those of the product, except for the signal at $\delta 4.14(\mathrm{H}-3)$. The major differences of the ${ }^{13} \mathrm{C}$-NMR spectra between the product and digoxigenin were the presence of a carbonyl carbon signal $(\delta 211.19)$ and the absence of the C-3 carbinol carbon signal $(\delta 66.70)$ in the product. In total, these data strongly suggest that the product is digoxigenone, a the product from digoxigenin oxidation at C-3.

The crystal structure and packing structure of the product are shown in Figs. 2 and 3, respectively. The selected bond lengths and bond angles are listed in Table 1.

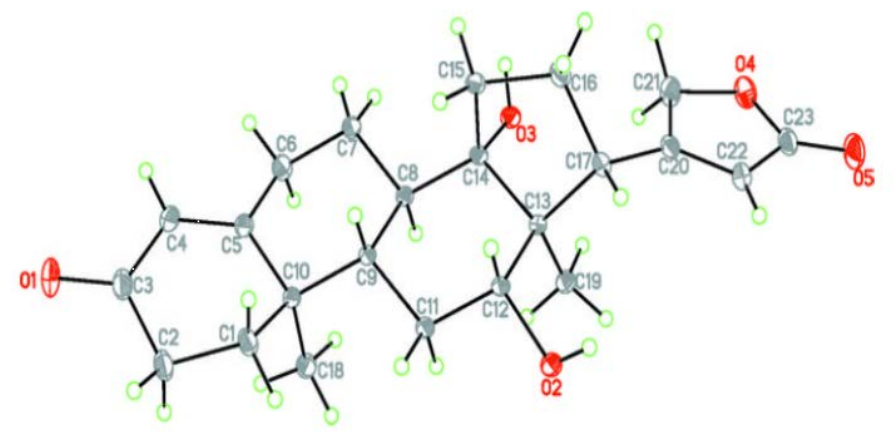

Fig. 2 Molecular structure of the product

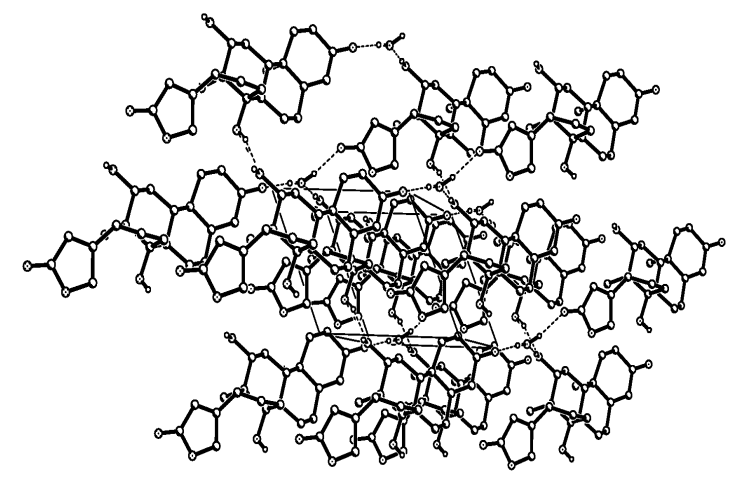

Fig. 3 Packing draw of the product

The crystal structure of the product consists of a digoxigenone molecule and one lattic water molecule. Compound digoxigenone has three fused six-membered rings (A/B/C) and two non-fused five-membered rings (D/E). As in other structures the cyclohexane rings $A, B$ and $C$ are in standard 
chair conformation. The five-membered rings $\mathrm{D}$ and $\mathrm{E}$ are trans-fused, while the other ring junctions are cis-fused. The 12-hydroxy is $\beta$ configuration with the torsion angle C9-C11-C12-O2 $=-179.6(2)^{\circ}$. The 14-hydroxy is $\beta$ configuration with the torsion angle C7-C8-C14-O3 $=-64.4(3)^{\circ}$. The orientation of the lactone ring is determined by the torsion angle $C(13)-C(17)-C(20)-C(22)=-113.1$ $(3)^{\circ}$.

Table 1 Selected Bond Lengths $(\AA)$ and Bond Angles $\left({ }^{\circ}\right)$ for the product

\begin{tabular}{|c|c|c|c|c|c|}
\hline Bond & Dist. & Bond & Dist. & Bond & Dist. \\
\hline $\mathrm{O}(1)-\mathrm{C}(3)$ & $1.229(3)$ & $\mathrm{C}(2)-\mathrm{H}(2 \mathrm{~A})$ & 0.9300 & $\mathrm{C}(7)-\mathrm{C}(15)$ & $1.539(3)$ \\
\hline $\mathrm{O}(2)-\mathrm{C}(9)$ & $1.442(2)$ & $\mathrm{C}(3)-\mathrm{C}(4)$ & $1.486(3)$ & $\mathrm{C}(8)-\mathrm{C}(9)$ & $1.510(3)$ \\
\hline $\mathrm{O}(2)-\mathrm{H}(2)$ & 0.8200 & $C(4)-C(5)$ & $1.520(3)$ & $\mathrm{C}(8)-\mathrm{H}(8 \mathrm{~A})$ & 0.9700 \\
\hline $\mathrm{O}(3)-\mathrm{C}(14)$ & $1.448(2)$ & $\mathrm{C}(4)-\mathrm{H}(4 \mathrm{~A})$ & 0.9700 & $\mathrm{C}(8)-\mathrm{H}(8 \mathrm{~B})$ & 0.9700 \\
\hline $\mathrm{O}(3)-\mathrm{H}(3)$ & 0.8200 & $\mathrm{C}(4)-\mathrm{H}(4 \mathrm{~B})$ & 0.9700 & $\mathrm{C}(9)-\mathrm{C}(10)$ & $1.561(3)$ \\
\hline $\mathrm{O}(4)-\mathrm{C}(22)$ & $1.349(3)$ & $C(5)-C(6)$ & $1.536(3)$ & $\mathrm{C}(9)-\mathrm{H}(9)$ & 0.9800 \\
\hline $\mathrm{O}(4)-\mathrm{C}(23)$ & $1.453(3)$ & $\mathrm{C}(5)-\mathrm{H}(5 \mathrm{~A})$ & 0.9700 & $\mathrm{C}(10)-\mathrm{C}(11)$ & $1.564(3)$ \\
\hline $\mathrm{O}(5)-\mathrm{C}(22)$ & $1.215(3)$ & $\mathrm{C}(5)-\mathrm{H}(5 \mathrm{~B})$ & 0.9700 & $\mathrm{C}(10)-\mathrm{C}(14)$ & $1.555(3)$ \\
\hline $\mathrm{C}(1)-\mathrm{C}(2)$ & $1.343(3)$ & $C(6)-C(7)$ & $1.557(3)$ & $\mathrm{C}(10)-\mathrm{C}(19)$ & $1.527(3)$ \\
\hline $\mathrm{C}(1)-\mathrm{C}(6)$ & $1.522(3)$ & $C(6)-C(18)$ & $1.546(3)$ & $\mathrm{C}(11)-\mathrm{C}(12)$ & $1.547(3)$ \\
\hline$C(1)-C(17)$ & $1.498(3)$ & $\mathrm{C}(7)-\mathrm{C}(8)$ & $1.537(3)$ & $\mathrm{C}(11)-\mathrm{C}(20)$ & $1.500(3)$ \\
\hline $\mathrm{C}(2)-\mathrm{C}(3)$ & $1.450(4)$ & & & & \\
\hline Angle & $\left({ }^{\circ}\right)$ & Angle & $\left(^{\circ}\right)$ & Angle & $\left({ }^{\circ}\right)$ \\
\hline $\mathrm{C}(22)-\mathrm{O}(4)-\mathrm{C}(23)$ & $108.40(18)$ & $\mathrm{C}(1)-\mathrm{C}(6)-\mathrm{C}(18)$ & 107.74(18) & $\mathrm{C}(8)-\mathrm{C}(9)-\mathrm{C}(10)$ & $113.10(17)$ \\
\hline $\mathrm{C}(2)-\mathrm{C}(1)-\mathrm{C}(17)$ & $120.6(2)$ & $C(5)-C(6)-C(18)$ & $110.29(16)$ & C(19)-C(10)-C(14) & 113.63(17) \\
\hline$C(2)-C(1)-C(6)$ & $122.5(2)$ & $C(1)-C(6)-C(7)$ & $109.26(16)$ & $\mathrm{C}(19)-\mathrm{C}(10)-\mathrm{C}(9)$ & 109.93(16) \\
\hline $\mathrm{C}(17)-\mathrm{C}(1)-\mathrm{C}(6)$ & 116.81(18) & $C(5)-C(6)-C(7)$ & 108.17(17) & $\mathrm{C}(14)-\mathrm{C}(10)-\mathrm{C}(9)$ & $108.05(15)$ \\
\hline$C(1)-C(2)-C(3)$ & $123.9(2)$ & $C(18)-C(6)-C(7)$ & $112.02(16)$ & $\mathrm{C}(19)-\mathrm{C}(10)-\mathrm{C}(11)$ & $114.55(16)$ \\
\hline $\mathrm{O}(1)-\mathrm{C}(3)-\mathrm{C}(2)$ & 121.7(3) & $C(8)-C(7)-C(15)$ & 109.69(15) & $\mathrm{C}(14)-\mathrm{C}(10)-\mathrm{C}(11)$ & 103.39(15) \\
\hline $\mathrm{O}(1)-\mathrm{C}(3)-\mathrm{C}(4)$ & $121.3(2)$ & $C(8)-C(7)-C(6)$ & $112.29(15)$ & $\mathrm{C}(9)-\mathrm{C}(10)-\mathrm{C}(11)$ & 106.77(16) \\
\hline$C(2)-C(3)-C(4)$ & $116.9(2)$ & $C(15)-C(7)-C(6)$ & $114.39(15)$ & $\mathrm{C}(20)-\mathrm{C}(11)-\mathrm{C}(10)$ & $116.74(17)$ \\
\hline$C(3)-C(4)-C(5)$ & $111.8(2)$ & $\mathrm{O}(2)-\mathrm{C}(9)-\mathrm{C}(8)$ & $106.00(16)$ & $\mathrm{C}(12)-\mathrm{C}(11)-\mathrm{C}(10)$ & $105.64(15)$ \\
\hline$C(1)-C(6)-C(5)$ & 109.32(17) & $\mathrm{O}(2)-\mathrm{C}(9)-\mathrm{C}(10)$ & 111.37(16) & C(20)-C(11)-C(12) & 112.77(16) \\
\hline
\end{tabular}

Intermolecular H-bonds are found in the crystal stacking. A part of stacking configuration is given in Fig. 3, which shows the molecular arrangement of the product . There were three types of intermolecular hydrogen bond interactions: between solvent water molecule and carbonyl of adjacent digoxigenone molecule, hydroxyl of digoxigenone molecule and hydroxyl of adjacent digoxigenone molecule, and hydroxyl of digoxigenone molecule and solvent water molecule. The detailed data of hydrogen bonds are listed in Table 2 .

Table 2 Hydrogen Bonds for the product

\begin{tabular}{lllll}
\hline $\mathrm{D}-\mathrm{H} \cdots \mathrm{A}$ & $\mathrm{d}(\mathrm{D}-\mathrm{H})$ & $\mathrm{d}(\mathrm{H} \cdots \mathrm{A})$ & $\mathrm{d}(\mathrm{D} \cdots \mathrm{A})$ & $\angle(\mathrm{DHA})$ \\
\hline $\mathrm{O} 2-\mathrm{H} 2 \cdots \mathrm{O} 6 \# 1$ & 0.82 & 1.99 & $2.808(3)$ & 173 \\
$\mathrm{O} 3-\mathrm{H} 3 \cdots \mathrm{O} 2 \# 2$ & 0.82 & 2.10 & $2.900(3)$ & 164
\end{tabular}




\begin{tabular}{|c|c|c|c|c|}
\hline O6-H1W $\cdots$ O1\#3 & $0.86(1)$ & $1.94(1)$ & $2.801(3)$ & $174(4)$ \\
\hline O6-H2W $\cdots$ O5\#4 & $0.86(1)$ & $1.91(2)$ & $2.741(4)$ & $162(5)$ \\
\hline
\end{tabular}

Symmetry codes: \#1 x-1, y, z-1; \#2 x+1, y, z; \#3 x+1, y+1, z; \#4x, y-1, z+1.\#1 x - 1,y,z - 1; \#2 x + 1,y,z; $\# 3 \mathrm{x}+1, \mathrm{y}+1, \mathrm{z} ; \# 4 \mathrm{x}, \mathrm{y}-1, \mathrm{z}+1$

\section{Acknowledgments}

This work was financially supported by the Applied Research Found of Luoyang Normal University (2012-YYJJ-004) and the Science and Technology Project of Henan Province (132102210394).

\section{References}

[1] W. Kreis, A. Hensel, U. Stuhlemmer: Planta Med Vol.64 (1998), p. 491

[2] T. Akera, Y.C. Ng: Life Sci Vol.48(1991), p. 97

[3] R.A. Newman, P. Yang, A.D. Pawlus, et al: Mol. Interv Vol.18(2008), p. 36

[4] W. Kreis, E. Reinhard: J. Biotechnology Vol.26(1992), p. 257

[5] R.M. Pádua, A.B. Oliveira, J.D. Souza Filho, et al: J. Braz. Chem. Soc Vol.16(2005), p. 614

[6] R.M. Pádua, A.B. Oliveira, J.D. Souza Filho, et al: J. Braz. Chem. Soc Vol.18(2007), p. 1303 